\title{
Correction to: Microbial synergy and stoichiometry in heap biooxidation of low-grade porphyry arsenic-bearing gold ore
}

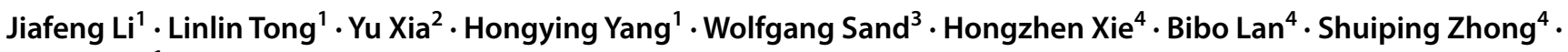 \\ Ali Auwalu ${ }^{1}$
}

Published online: 15 April 2020

C Springer Japan KK, part of Springer Nature 2020

\section{Correction to: Extremophiles}

https://doi.org/10.1007/s00792-020-01160-6

In the original publication the section heading "Classification of microorganisms" appearing above the sub-section "Air and liquid circulation in the heap" in page four is incorrect. The correct section heading should be read as "Results and discussion".

Publisher's Note Springer Nature remains neutral with regard to jurisdictional claims in published maps and institutional affiliations.

The original article can be found online at https://doi.org/10.1007/ s00792-020-01160-6.

Linlin Tong

tongll@smm.neu.edu.cn

1 School of Metallurgy, Northeastern University, Shenyang 110819, China

2 School of Chemical and Environmental, China University of Mining and Technology, Beijing 100083, China

3 Biofilm Centre, Aquatische Biotechnologie, Universität Duisburg-Essen, Universitätsstraße 5, 45141 Essen, Germany

4 State Key Laboratory of Comprehensive Utilization of Low-Grade Refractory Gold Ores, Zijin Mining Group Co., Ltd, Shanghang 364200, China 